\title{
Evidence of an association between the survival of embryos and the periovulatory plasma progesterone concentration in the ewe*
}

\author{
C. J. Ashworth†, D. I. Sales and I. Wilmut \\ AFRC Institute of Animal Physiology and Genetics Research\$, Edinburgh Research Station, Roslin, \\ Midlothian, EH25 9PS, UK
}

\begin{abstract}
Summary. Plasma progesterone concentration and embryo survival were determined during successive pregnancies in ewes throughout one breeding season. The probability of an embryo surviving was associated with the progesterone concentration on the days around ovulation, with the timing of the increase from periovulatory to luteal values, and with the rate at which progesterone concentrations increased. Individual embryo survival decreased both as the number of corpora lutea increased, and towards the end of the breeding season; the latter effect could be explained entirely by differences in progesterone concentration. Considerable variation in progesterone secretion and in embryo survival was observed within the same ewes during successive pregnancies. Such variability in progesterone concentrations during early pregnancy may be a cause of some embryo mortality.
\end{abstract}

Keyw'ords: embryo survival; fertility; progesterone; sheep; season

\section{Introduction}

In ewes maintained under good husbandry conditions, and in the absence of recognized stress, $20-30 \%$ of fertilized eggs are not represented by lambs at birth (Edey, 1976). Chromosomal anomalies have been detected in about $6 \%$ of Day- 2 or Day-3 sheep embryos (Long \& Williams, 1980 ) and as such do not account for all of the natural embryo loss. The causes of the additional losses are unclear. It has been suggested that some embryos may die in mated ewes because their rate of development is inappropriate to their maternal environment (Wilmut \& Sales, 1981). Some of this 'asynchrony' may occur through variation in the sequence of progesterone concentrations following the LH peak.

The importance of progesterone during early pregnancy in sheep has been well established. Studies using ovariectomized ewes have revealed 3 important phases of progesterone secretion after mating (Miller \& Moore, 1976; Wilmut et al., 1985a). First, it is essential to have a low concentration (probably $0 \cdot 1-0 \cdot 2 \mathrm{ng} / \mathrm{ml}$ ) of progesterone from Day 1 after mating. Second, the concentration must increase during the period from Day 3 to Day 7 after mating to values typical of those observed during the luteal phase $(3-6 \mathrm{ng} / \mathrm{ml})$. Third, it is important that this luteal-phase value is adequate for the maintenance of pregnancy.

It has been suggested that some embryo mortality may be associated with the ability of an animal to live and reproduce in a wide variety of environments (Wilmut et al., 1985b). Several environmental factors such as nutrition (Williams \& Cumming, 1982) and the stage of the breeding

\footnotetext{
* Reprint requests to Dr I. Wilmut.

†Present address: Rowett Research Institute, Greenburn Road, Bucksburn, Aberdeen AB2 9SB, UK.

\$Formerly: Animal Breeding Research Organisation.
} 
season (Rhind et al., 1978) affect progesterone concentrations. These factors also influence embryo survival (Cumming et al., 1975; Lightfoot, 1986). Moreover, low pregnancy rates in ewes on a high plane of nutrition appear to be due to inadequate circulating progesterone concentrations, since pregnancy rate was restored to that in control ewes by administration of progesterone during the luteal phase (Parr et al., 1987). In this way, progesterone concentrations may vary with environmental conditions, and may in turn affect the number of embryos surviving. In the present study, we have tested this hypothesis by comparing the progesterone profiles during pregnancies in which all embryos survived with profiles in pregnancies that suffered loss; this comparison was made both within ewes and between ewes. Thus the relevance of the 3 progesterone phases to natural pregnancy, and the importance of the periovulatory progesterone in particular, have been assessed. Preliminary reports of this experiment have been published previously (Ashworth et al., 1984; Wilmut et al., 1986).

\section{Materials and Methods}

Experimental animals. Thirty (30) ABRO Damline ewes, between 1 and 5 years of age, were used in this experiment. This is a synthetic line produced by crossing Finnish Landrace (47\%), East Friesland (24\%), Border Leicester $(17 \%)$ and Dorset Horn (12\%) breeds, and selecting for 8-week litter weight of lambs weaned (Smith et al., 1979). The ewes for the present experiment had been discarded from the selection flock, but were all in good health and the majority (28) were of proven fertility.

Ewes were housed indoors during periods of blood collection, and for $24 \mathrm{~h}$ before and after surgery. Whilst indoors, they were fed on hay supplemented with a proprietary complete diet. Paddock feeding consisted of hay and turnips ad libitum. Oestrous cycles were synchronized by 2 intramuscular injections of $100 \mu \mathrm{g}$ cloprostenol, a prostaglandin analogue (Estrumate: ICI plc, Macclesfield, Cheshire, UK), given 9 days apart. Oestrus was confirmed by twice daily examinations using vasectomized rams. Ewes were hand-mated at 0 and $12 \mathrm{~h}$ after the onset of the second oestrus after synchronization. On both occasions, at least 2 rams were used from a group of 7 . After mating, oestrous activity was monitored daily using a vasectomized ram.

Blood samples were collected by jugular puncture at $07: 00,14: 00$ and $21: 00 \mathrm{~h}$ for 7 days around the time of mating. These 7 days were chosen so that oestrus was expected on the 3rd day. Subsequently, blood samples were obtained twice daily, at 08:00 and 16:00 h until Day 16. Immediately after collection, blood samples were centrifuged and the plasma stored at $-20^{\circ} \mathrm{C}$.

The numbers and distribution of corpora lutea and fetuses were recorded during a mid-ventral laparotomy, performed within 2 days of an observed return to oestrus, or 30 days after mating in the absence of oestrus. Anaesthesia was induced by a single intravenous injection of $8-20 \mathrm{ml} 10 \%(\mathrm{w} / \mathrm{v})$ thiopentone sodium (Intraval: May and Baker Ltd, Dagenham, UK) and maintained by a mixture of oxygen, nitrous oxide and halothane (Fluothane: ICI plc) in a semi-closed system. Immediately after the surgery, $100 \mu \mathrm{g}$ cloprostenol were administered to pregnant ewes to induce abortion.

Experimental design. The regimen described above was repeated on the same animal population during September, November, January and March of a single breeding season. In this way, ewes were allowed at least one oestrous cycle free from experimentation between successive sample series. Blood samples were collected from only those ewes which showed their 2 nd oestrus after synchronization within a predefined 5-day interval.

Only 10 ewes showed oestrus within the prescribed 5-day period during November. It was presumed that the products of conception had not been removed, preventing a return to cyclicity. The interval between matings was therefore increased. Only those ewes which had not been mated in November were synchronized for January mating. Consequently, the maximum number of sample series per ewe was 3. After observations in November or January, an additional injection of $100 \mu \mathrm{g}$ cloprostenol was given 8 days after surgery to promote the return to normal oestrous cycles. A summary of the number of ewes studied each month, and the outcome of their pregnancies is shown in Table 1.

One ewe did not show oestrus within the predefined 5-day interval during any of the 4 sampling periods. Of the remaining 29 ewes, there were 16 ewes with 3 oestrous cycles represented, 11 ewes with 2 and 2 ewes with 1 cycle. Thus a total of 72 series of blood samples were collected.

This design permitted several pregnancies to be monitored in the same ewes during one breeding season. Both the repeatability and the relation to embryo survival of various aspects of the progesterone profile were determined.

Radioimmunoassay of plasma samples. It was not possible to assay all of the plasma samples available because of limited access to suitable laboratory facilities. A subset of 18 of the 29 ewes was chosen; this consisted of 15 ewes with 3 series and 3 ewes with 2 series of blood samples (a total of 51 cycles represented). All of these series of blood samples were assayed for both $\mathrm{LH}$ and progesterone. 
LH concentrations were measured in series of 8 consecutive plasma samples per oestrous cycle. The series were chosen such that the 3 rd sample was closest to the time of first mating. All samples were measured in the same assay, using a doubie-antibody precipitation method (Webb et al., 1985). The minimum detectable dose was $0.443 \mathrm{ng}$ $\mathrm{LH} / \mathrm{ml}$. The intra-assay coefficient of variation was $4.9 \%$.

Progesterone radioimmunoassays were performed as described previously (Ashworth et al., 1987). All of the series of samples collected from a ewe during one sampling period were measured in the same assay. Progesterone concentrations were determined in 2 samples collected on each day: either from samples collected at 07:00 and 21:00 h or at 08:00 and 16:00 h. No assay contained samples from the same animal acquired during different sampling periods. Plasma samples were randomized within assays.

The reliability criteria for this assay have been described by Ashworth (1985). The minimal detectable dose, defined as the lowest dose significantly different from the zero standard value, was $15.0 \pm 1.5 \mathrm{pg} /$ tube (geometric mean \pm s.e.m.). Aliquants of double-distilled deionized water included in each assay to estimate the solvent blank gave values consistently lower than the minimum detectable dose. The mean extraction efficiency was $76.8 \pm 1.96 \%$ (s.e.m.). The inter-assay coefficients of variation were obtained by using 4 standard quality control samples with mean progesterone concentrations of $0.19 \pm 0.08,1.56 \pm 0.27,2.54 \pm 0.42$ and $6.84 \pm 0.96 \mathrm{ng} / \mathrm{ml}$; they were $44.9,14.1$, 16.7 and $17.3 \%$ respectively. The intra-assay coefficient of variation averaged $6.3 \%$ for duplicate determinations of ovariectomized ewe plasma placed at the beginning and end of each assay.

Statistical analysis. Sample times were expressed relative to the time at which the highest concentration of LH was detected $(0 \mathrm{~h})$. Progesterone estimates were $\log _{10}$ transformed and various summary statistics were calculated. The mean periovulatory value was defined as the mean progesterone concentration from samples collected on Days 0 and 1. The mean luteal level was calculated as the mean of progesterone values from samples collected on Days 11 and 12. The data from two sample series were excluded from subsequent analyses because the mean luteal level could not be estimated. In one case, the progesterone concentrations never rose above periovulatory levels and the ewe returned to oestrus within 12 days. In the other case, progesterone concentrations rose normally but dropped abruptly at the end of Day 10 and remained low for the next 5 days.

The timing of the progesterone rise was assessed by first smoothing the transformed progesterone estimates; the smoothed value at each time point was taken as the unweighted average of the estimate at that time and at the 2 adjacent times. The times were determined at which the smoothed progesterone concentrations were closest to the $25 \%, 50 \%$ and $75 \%$ levels of difference between mean periovulatory and mean luteal concentration in that ewe in that sample series (T25, T50, T75). A further parameter was defined by finding the first occurrence of 2 consecutive progesterone values greater than $0.5 \mathrm{ng} / \mathrm{ml}$; the time at which the first of these was taken was called $\mathrm{T} 0.5$. The rate of increase in progesterone concentrations was estimated from the slope of the linear regression on time of the 7 unsmoothed transformed values centred on T50.

The embryo survival data from all ewes in the experiment were analysed using a general linear model with a logit link function (Nelder \& Wedderburn, 1972), as implemented in the computer program GLIM (Baker \& Nelder, 1978). The binomial trait analysed was the number of corpora lutea represented by a fetus at Day 30 . The effects included were the animal, the stage of the breeding season and the number of ovulations; each effect was tested after adjusting for all other effects in the model. In particular, the effects of season and ovulation rate were determined after allowing for the variation between ewes in embryo survival. To allow comparison with other published work, a similar analysis was carried out using least squares and the analysis of variance on the proportion of represented ovulations at Day 30 . This allowed the repeatability of embryo survival to be estimated by equating mean squares and their expectations.

Further analyses were performed on the subset of the embryo survival data for which progesterone information was available; this comprised 49 cycles from 18 ewes. In these analyses, all the progesterone profile traits were included in the model, and an attempt was made to find the best subset, mainly by using backwards elimination. In GLIM analyses of binomial traits, it is usual practice to use an approximate test of significance in which deviance differences are compared with a $\chi^{2}$ distribution. For small sample sizes, this approximation can be poor. Simulation showed that this was the case here, with the $\chi^{2}$ tests giving too many significant results. Therefore, all of the significance levels in this analysis were obtained by simulation.

The progesterone variables were analysed for the effects of individual ewes, number of ovulations and the stage of the breeding season, using least squares and the analysis of variance. The repeatabilities of the mean periovulatory and mean luteal progesterone values were estimated; these are a measure of the importance of variation between ewes over different oestrous cycles.

\section{Results}

Overall summaries of the observations on embryo survival are given in Tables 1,2 and 3 . The analysis of these data showed that there was a significant $(P<0.01)$ effect of the number of corpora lutea on embryo survival; this may be summarized as a linear decline in survival with increasing numbers of corpora lutea. The effect of the stage of the breeding season was also significant $(P<0 \cdot 05)$, apparently because embryo survival was lower in March. 
Table 1. Ewe numbers and pregnancy outcome during each month studied

\begin{tabular}{lcccc}
\hline & September & November & January & March \\
\hline No. of ewes bled & 19 & 10 & 17 & 26 \\
No. of ewes from which samples & 16 & 10 & 8 & 17 \\
$\quad$ were assayed & 18 & 8 & 17 & 19 \\
No. of pregnant ewes & 45 & 22 & 42 & 53 \\
No. of corpora lutea & 32 & 15 & 36 & 34 \\
No. of fetuses & 63 & 50 & 71 & 54 \\
\% Ewes with total embryo & 64 sival & & & \\
\hline
\end{tabular}

Table 2. Effect of ovulation number on embryo survival and pregnancy

\begin{tabular}{|c|c|c|c|c|c|c|}
\hline & \multicolumn{5}{|c|}{ No. of ovulations } & \\
\hline & 1 & 2 & 3 & 4 & 5 & \\
\hline \multicolumn{7}{|l|}{ Fetal number } \\
\hline 0 & 2 & 6 & 0 & 1 & 1 & \\
\hline 1 & 8 & 7 & 0 & 0 & 0 & \\
\hline 2 & & 27 & 9 & 2 & 0 & \\
\hline 3 & & & 8 & 0 & 1 & \\
\hline 4 & & & & 0 & 0 & \\
\hline 5 & & & & & 0 & \\
\hline No. of observations & 10 & 40 & 17 & 3 & 2 & \\
\hline$\%$ Ewes pregnant on Day 30 & 80 & 85 & 100 & 67 & 5 & \\
\hline$\%$ Ovulations represented & 80 & 76 & 82 & 33 & 30 & $P<0.01$ \\
\hline
\end{tabular}

Table 3. Effect of the stage of the breeding season on pregnancy and embryo survival

\begin{tabular}{|c|c|c|c|c|c|}
\hline & September & November & January & March & \\
\hline $\begin{array}{l}\text { No. of observations } \\
\text { No. pregnant on Day } 30 \\
\text { Mean ( } \pm \text { s.e.m.) no. of ovulations } \\
\% \text { Ovulations represented by a fetus }\end{array}$ & $\begin{array}{c}19 \\
18(95 \%) \\
2 \cdot 37 \pm 0 \cdot 22 \\
\frac{73}{}\end{array}$ & $\begin{array}{c}10 \\
8(80 \%) \\
2 \cdot 20 \pm 0 \cdot 33 \\
\frac{68}{0}\end{array}$ & $\begin{array}{c}17 \\
17(100 \%) \\
2 \cdot 47 \pm 0 \cdot 19 \\
\frac{86}{}\end{array}$ & $\begin{array}{c}26 \\
19(73 \%) \\
2 \cdot 08 \pm 0 \cdot 15 \\
\frac{63}{2}\end{array}$ & $P<0.05$ \\
\hline
\end{tabular}

The GLIM analysis of these data showed that there was significant variation between different ewes in embryo survival $(P<0.05)$. However, the conventional least squares analysis gave a repeatability of zero, as the ewe mean square was less than the residual mean square. A further least squares analysis, which weighted each survival proportion by the number of corpora lutea on which it was based, gave a repeatability estimate of $2 \%$; this did not differ significantly from zero.

Data from the cycles in which progesterone estimates were included in the analysis are presented in Table 4. The analyses of this subset of the data again suggested that there were differences in embryo loss between animals, although this was not significant; the significance of other factors was assessed from the within-animal analyses.

The proportion of embryos lost was associated with periovulatory progesterone concentrations, with the estimated time at which progesterone was halfway between periovulatory and luteal values (T50), and with the rate of increase in progesterone values at that time. The periovulatory concentrations had a significant quadratic effect with worst survival occurring just below the mean level of $0.14 \mathrm{ng} / \mathrm{ml}$. Alternative models involving an increase from an asymptote or treating certain cycles as outliers did not fit as well. The timing of the rise in progesterone had a linear effect on survival 
Table 4. Number of fetuses, ovulation rate and progesterone parameters during each pregnancy studied

\begin{tabular}{|c|c|c|c|c|c|c|c|c|}
\hline \multirow[b]{2}{*}{$\begin{array}{l}\text { Ewe } \\
\text { no. }\end{array}$} & \multirow[b]{2}{*}{ Month } & \multirow[b]{2}{*}{$\begin{array}{l}\text { Ovulation } \\
\text { rate }\end{array}$} & \multirow[b]{2}{*}{ Fetuses } & \multicolumn{4}{|c|}{ Progesterone profile parameters } & \multirow{2}{*}{$\begin{array}{l}\text { Interoestrous } \\
\text { interval } \dagger \\
\text { (days) }\end{array}$} \\
\hline & & & & $\begin{array}{l}\text { Periovulatory } \\
\qquad\left(\log _{10} \mathrm{ng} / \mathrm{ml}\right)\end{array}$ & Luteal & $\begin{array}{l}\text { T50 } \\
\text { (h) }\end{array}$ & Increase* & \\
\hline 48 & January & 2 & 2 & -0.638 & $0 \cdot 490$ & 107 & $0 \cdot 238$ & \\
\hline 48 & March & 2 & 0 & -0.782 & 0.449 & 97 & 0.282 & $>30$ \\
\hline $5 \mathrm{I}$ & September & 3 & 2 & -0.892 & 0.683 & 72 & 0.390 & \\
\hline 51 & November & 2 & 2 & -0.891 & $0 \cdot 591$ & 79 & 0.536 & \\
\hline $5 I$ & March & 1 & 1 & -0.819 & 0.513 & 83 & $0 \cdot 321$ & \\
\hline 136 & September & 2 & 1 & -1.225 & 0.562 & 66 & 0.557 & \\
\hline 136 & November & 1 & 1 & -0.836 & 0.561 & 80 & 0.400 & \\
\hline 136 & March & 1 & 1 & -0.915 & 0.419 & 90 & $0 \cdot 309$ & \\
\hline 146 & September & 2 & 2 & -0.960 & $0 \cdot 560$ & 57 & 0.420 & \\
\hline 146 & January & 2 & 2 & -0.994 & 0.739 & 57 & $0 \cdot 398$ & \\
\hline 146 & March & 2 & 0 & -1.098 & 0.586 & 89 & $0 \cdot 262$ & 18 \\
\hline 184 & September & 2 & 2 & -1.021 & 0.466 & 73 & $0 \cdot 370$ & \\
\hline 184 & November & 1 & 0 & -0.878 & 0.589 & 89 & $0 \cdot 245$ & 23 \\
\hline 184 & March & 2 & 2 & -1.085 & $0 \cdot 551$ & 83 & 0.484 & \\
\hline 203 & September & 2 & 2 & -0.635 & 0.419 & 112 & $0 \cdot 276$ & \\
\hline 203 & November & 3 & 3 & -0.942 & 0.686 & 72 & $0 \cdot 384$ & \\
\hline 223 & September & 2 & 0 & -0.881 & 0.395 & 131 & $0 \cdot 369$ & 21 \\
\hline 223 & November & 4 & 2 & -0.670 & 0.688 & 89 & $0 \cdot 312$ & \\
\hline 223 & March & 2 & 2 & -0.907 & 0.622 & 83 & $0 \cdot 321$ & \\
\hline 287 & January & 2 & 2 & -0.899 & 0.577 & 91 & 0.226 & \\
\hline 287 & March & 2 & 0 & $-1 \cdot 145$ & 0.444 & 83 & 0.626 & $>30$ \\
\hline 331 & September & 2 & 1 & -0.901 & 0.495 & 81 & $0 \cdot 184$ & \\
\hline 331 & March & 2 & 1 & -0.977 & $0 \cdot 210$ & 139 & $0 \cdot 253$ & \\
\hline 332 & September & 2 & 2 & -0.848 & 0.442 & 91 & $0 \cdot 161$ & \\
\hline 332 & January & 2 & 2 & -0.967 & 0.406 & 107 & 0.225 & \\
\hline 332 & March & 2 & 2 & $-0 \cdot 940$ & 0.442 & 97 & 0.377 & \\
\hline 361 & September & 3 & 2 & -1.264 & 0.491 & 67 & 0.507 & \\
\hline 361 & November & 2 & 0 & -1.075 & 0.383 & 79 & 0.410 & $>30$ \\
\hline 361 & March & 2 & 0 & -0.947 & 0.406 & 83 & 0.360 & 20 \\
\hline 409 & September & 1 & 1 & -0.863 & $0 \cdot 232$ & 91 & $0 \cdot 228$ & \\
\hline 409 & November & 2 & 1 & $-1 \cdot 130$ & $0 \cdot 610$ & 79 & 0.449 & \\
\hline 409 & March & 4 & 0 & -0.829 & 0.543 & 83 & 0.333 & 18 \\
\hline 432 & September & 2 & 2 & $-1 \cdot 340$ & 0.420 & 97 & 0.414 & \\
\hline 432 & January & 2 & 2 & -0.844 & 0.660 & 81 & 0.298 & \\
\hline 432 & March & 1 & 0 & -1.062 & 0.507 & 138 & 0.093 & 15 \\
\hline 492 & September & 4 & 2 & -0.634 & 0.755 & 88 & $0 \cdot 219$ & \\
\hline 492 & January & 3 & 3 & -0.615 & 0.745 & 98 & 0.254 & \\
\hline 553 & September & 3 & 2 & -0.898 & 0.585 & 90 & 0.344 & \\
\hline 553 & January & 3 & 2 & -0.944 & 0.559 & 67 & $0 \cdot 364$ & \\
\hline 553 & March & 3 & 3 & -0.782 & 0.693 & 79 & 0.424 & \\
\hline 596 & September & 2 & 2 & -1.026 & 0.367 & 90 & $0 \cdot 363$ & \\
\hline 596 & January & 3 & 2 & $-1 \cdot 179$ & 0.629 & 66 & 0.456 & \\
\hline 596 & March & 2 & 2 & -1.093 & 0.403 & 73 & $0 \cdot 352$ & \\
\hline 3561 & September & 2 & 2 & -0.952 & 0.470 & 83 & 0.346 & \\
\hline 3561 & November & 3 & 2 & -0.785 & 0.551 & 72 & 0.396 & \\
\hline 3561 & March & 2 & 1 & -1.087 & 0.481 & 83 & $0 \cdot 311$ & \\
\hline 3562 & September & 2 & 2 & -0.641 & 0.407 & 98 & 0.291 & \\
\hline 3562 & November & 3 & 3 & $-1 \cdot 220$ & 0.655 & 86 & 0.434 & \\
\hline 3562 & March & 3 & 3 & $-1 \cdot 136$ & 0.511 & 83 & 0.451 & \\
\hline
\end{tabular}

*Increase is slope of regression at T50 of $\log _{10}$ progesterone on time.

$\uparrow$ For ewes returning to oestrus before Day 30 .

$(P<0.05)$, with survival being higher in ewes in which T50 was reached earlier. The rate of increase at this time also had a significant effect and again the effect was quadratic $(P<0 \cdot 01)$. The intermediate optimum corresponded to multiplicative increase of about 2.5 times per day, which was 
Table 5. Effect of ovulation number on progesterone parameters

\begin{tabular}{|c|c|c|c|c|c|}
\hline No. of ovulations & 1 & 2 & 3 & 4 & \\
\hline No. of observations & 6 & 29 & 11 & 3 & \\
\hline Periovulatory conc. (ng/ml) & $0.18 \pm 0.03$ & $0.12 \pm 0.01$ & $0.09 \pm 0.01$ & $0 \cdot 18 \pm 0 \cdot 04$ & $P<0.05$ \\
\hline Luteal conc. (ng/ml) & $2.66 \pm 0.28$ & $3 \cdot 25 \pm 0 \cdot 14$ & $4 \cdot 22 \pm 0.34$ & $4.33 \pm 0.62$ & $P<0.01$ \\
\hline T25 (h) & $68 \pm 8$ & $67 \pm 3$ & $55 \pm 6$ & $47 \pm 11$ & \\
\hline T50 (h) & $105 \pm 8$ & $88 \pm 3$ & $77 \pm 6$ & $78 \pm 11$ & \\
\hline T75 (h) & $143 \pm 9$ & $119 \pm 4$ & $113 \pm 7$ & $138 \pm 13$ & \\
\hline $\mathrm{T} 0.5(\mathrm{~h})$ & $105 \pm 10$ & $85 \pm 4$ & $73 \pm 8$ & $75 \pm 14$ & \\
\hline Daily increase* & $0.15 \pm 0.04$ & $0.36 \pm 0.02$ & $0.42 \pm 0.03$ & $0.28 \pm 0.03$ & $P<0.01$ \\
\hline
\end{tabular}

Progesterone values are geometric means from the least squares analysis.

*Increase is slope of regression at $\mathrm{T} 50$ of $\log _{10}$ progesterone on time.

Table 6. Effect of the stage of the breeding season on progesterone parameters

\begin{tabular}{lccccc}
\hline & September & November & January & March & \\
\hline No. of observations & 16 & 9 & 8 & 16 & \\
Periovulatory conc. $(\mathrm{ng} / \mathrm{ml})$ & $0 \cdot 13 \pm 0.01$ & $0 \cdot 13 \pm 0.02$ & $0 \cdot 17 \pm 0.03$ & $0 \cdot 12 \pm 0.01$ & \\
Luteal conc. $(\mathrm{ng} / \mathrm{ml})$ & $3 \cdot 13 \pm 0 \cdot 21$ & $3 \cdot 98 \pm 0 \cdot 31$ & $3 \cdot 77 \pm 0 \cdot 36$ & $3 \cdot 36 \pm 0.20$ & $P<0.05$ \\
T25 (h) & $60 \pm 5$ & $59 \pm 6$ & $59 \pm 7$ & $59 \pm 4$ & \\
T50 (h) & $88 \pm 5$ & $84 \pm 6$ & $85 \pm 7$ & $91 \pm 5$ & \\
T75 (h) & $131 \pm 6$ & $118 \pm 7$ & $134 \pm 8$ & $131 \pm 5$ & \\
T0.5 (h) & $89 \pm 7$ & $77 \pm 8$ & $83 \pm 9$ & $89 \pm 6$ \\
Daily increase* & $0.29 \pm 0.03$ & $0.34 \pm 0.03$ & $0.25 \pm 0.04$ & $0.32 \pm 0.02$ & \\
\hline
\end{tabular}

Progesterone values are geometric means from the least squares analysis.

*Increase is slope of regression at $\mathrm{T} 50$ of $\log _{10}$ progesterone on time.

also close to the mean level for this trait. None of the other profile traits (T25, T75, T0.5, mean luteal) gave a significant improvement to the model for embryo survival. When the effect of animals was dropped from the survival analysis, the conclusion about which of the profile parameters were important was not affected, although the estimated size of the effects did change.

When progesterone was included in the statistical model, the effect of the stage of the breeding season was no longer significant, suggesting that seasonal differences in survival are mediated by changes in plasma progesterone concentration or that both arise from the same cause. The effect of the number of corpora lutea on embryo survival, however, was only partly attributable to differences in progesterone concentration. From the 49 cycles included in this part of the study only 3 led to a return to oestrus before Day 20. In such situations it is not possible to determine whether the lack of pregnancy is due to fertilization failure or embryo mortality, because the duration of the ovine oestrous cycle is typically between 14 and 19 days (Terrill, 1974). All cases of potential fertilization failure occurred following mating in March. The analyses were rerun giving these three observations an order of magnitude less weight. The result was that season was no longer significant, but the significance of the other terms in the model was hardly affected.

The effects of ovulation number and the stage of the breeding season on the progesterone profile parameters are given in Tables 5 and 6 respectively. The number of ovulations significantly affected periovulatory progesterone concentrations $(P<0.05)$, luteal progesterone values $(P<0.01)$ and the rate of progesterone increase $(P<0.01)$. The only significant effect of the stage of the breeding season was on luteal progesterone concentrations $(P<0.05)$. The mean square for animals in the analysis of variance was greater than the error mean square for all traits except $\mathrm{T} 0 \cdot 5$, but was not significant. The estimated repeatabilities of mean periovulatory, mean luteal progesterone values, for T50 and for rate of progesterone increase were 29,28, 23 and $29 \%$ respectively, with a standard error of $19 \%$ in each case. Although these estimates were obtained from a selected sample of animals, any bias should be small relative to their standard errors. 


\section{Discussion}

This experiment has revealed an association between differences in plasma progesterone concentrations and embryo survival in naturally mated ewes. It has also provided new information on the patterns of progesterone secretion and variation in fertility during the breeding season. It was possible to detect these associations because the experimental procedure allowed the study of the first 30 days of up to 3 pregnancies in a ewe in a single breeding season. As most pre-natal loss in sheep occurs during the first 3 weeks of pregnancy, the number of fetuses surviving to Day 30 will provide a good estimate of the projected lambing rate. In view of the significant variation between ewes in embryo survival, this represents a major increase in sensitivity compared with the typical one pregnancy per season, and allows the study of within-animal effects free of the confounding effects of years, age and parity.

Although this experiment did not distinguish between fertilization failure and embryo loss, data on the inter-oestrous interval suggest that the former was minimal and are consistent with the review by Kelly (1984), which indicated that in mature ewes $90-96 \%$ of eggs ovulated are fertilized. In the current study, the 3 cases of potential fertilization failure only affected the conclusions regarding the effects of season.

This study provides the first direct evidence for an association between the concentrations of progesterone around the time of mating and embryo survival in mated ewes under standard conditions of husbandry. However, the apparently quadratic nature of the effect is difficult to explain. Our earlier work, in which embryos were transferred to ovariectomized ewes, showed that some progesterone was essential between Days 1 and 4 of pregnancy (Wilmut et al., 1985a). Lee et al. (1985) also reported that the proportion of pregnancies was greater in cows exhibiting higher progesterone concentrations on Days 1-3. Circulating progesterone concentrations during the periovulatory period are considered to consist of similar contributions from the adrenal gland and the ovary. Progesterone concentrations in preovulatory follicles may increase at this time, as indicated by higher follicular fluid (England et al., 1981; McNatty et al., 1981) and ovarian venous plasma concentrations (Wheeler et al., 1975). There are some differences in the conclusions about the associations with progesterone from those in our preliminary reports (Ashworth et al., 1984; Wilmut et al., 1986). The differences arise from a change in the samples chosen to define mean periovulatory and mean luteal values, and a change in the statistical tests used to assess significance.

The association between the establishment of pregnancy and differences in progesterone concentration could reflect several effects which will be considered in turn. These results could reflect events in follicular maturation. Corpora lutea which secrete low amounts of progesterone may be formed from inadequate follicles, as indicated by White et al. (1987). Oocytes and embryos arising from such follicles may not have the potential for normal fertilization and development. Nevertheless, the incidence of fertilization failure in mature ewes is low (Kelly, 1984).

Alternatively, the embryo may modify maternal function. It has been demonstrated that zygotes from mice and primates release a platelet-activating factor (PAF) (O'Neill, 1987). In humans, the production of PAF is correlated with the establishment of pregnancy after in-vitro fertilization (O'Neill et al., 1987). It is possible that embryo-derived PAF may act at the level of the corpus luteum. PAF has been shown to stimulate the polyinositol pathway, the second messenger system mediating progesterone production (Lapetina, 1982). If sheep embryos release a similar factor, they could be capable of increasing progesterone production. The only direct study found no significant difference between the production rate or the metabolic clearance rate of progesterone between cyclic and pregnant ewes at the same interval after oestrus (Bedford et al., 1972). However, these conclusions were based on rather few data, so further work is needed.

Wilmut \& Sales (1981) predicted that the timing of the switch from periovulatory to luteal concentrations of progesterone would influence survival. This could arise either through the known effects of progesterone on the uterine environment, or through natural differences between rates of uterine and embryo development. The association between embryo survival and the time taken for 
progesterone concentrations to reach the geometric mean of periovulatory and luteal values provides some support for this hypothesis. The apparent existence of an intermediate optimum for the rate of increase in progesterone concentrations is believed to be more important. Unless there is communication between the embryo and uterus before Day 4, faster or slower rates of increase imply an increasing degree of asynchrony between embryo and ewe as the pregnancy proceeds. It had been postulated earlier that such asynchrony could be a contributory factor to embryo loss under normal conditions (Wilmut et al., 1985b).

There is therefore some evidence that: (a) an inadequate follicle could give rise to low progesterone levels and a moribund embryo; (b) a viable embryo could influence progesterone concentrations via PAF; and (c) progesterone can influence timing of uterine changes or could be an indicator of the present stage of development and hence be associated with asynchronous losses. It is not clear which of these possibilities is the most important.

There are several possible explanations for the observed seasonal differences. They could be due to a higher incidence of fertilization failure in March, or perhaps to the cumulative effects of the experimental procedures. Alternatively, they could be a direct effect explicable through differences in progesterone concentration. Variation in progesterone secretion may be primarily of environmental rather than genetic origin, which is consistent with the low repeatabilities found. In this way, progesterone concentration may be a reflection both of external conditions and of an animal's own body condition and may affect the number of embryos carried. The levels of embryo survival observed in field situations may reflect the best compromise between the ability to breed in a range of environments and the need for the majority of eggs to develop to term.

The repeatability of embryo survival, from observations in successive years on ovulation rate and the resulting litter size in ewes, was reported as $0.07 \pm 0.04$ by Hanrahan (1982). This is consistent with the repeatability calculated in the same way in this experiment, but not with the finding of significant ewe variation in the GLIM analysis. The conventional least squares analysis of survival data is unsatisfactory in several ways; it assumes that the data are normally distributed, that they are additive on the observed scale, and that they have equal variance. This last objection can be partly overcome by transforming the data and doing a weighted analysis, but this is rarely practised. In contrast, the GLIM analysis makes reasonable assumptions about the data, and so should give a much more realistic assessment of the importance of the various factors influencing survival. Unfortunately it is harder to translate its finding of significant ewe variation into a traditional measure such as a repeatability, and some of this variation could be due to differences in ewe age. The different conclusion from the GLIM analysis does suggest that previous workers may have underestimated the importance of individual variation in embryo survival.

Selection for improved embryo survival in sheep is difficult to achieve in practice. However, the methods used in this study show that it is possible to make multiple measurements within a breeding season. Providing that care is exercised to minimize surgical trauma and adhesions this could be as important an advance as the use of laparoscopy has been in selection for ovulation rate. Alternatively, it would be possible to select on a physiological trait associated with survival. Some of the progesterone profile traits considered in this study might be candidates for such selection, but their repeatabilities appear to be low. This may reflect the range of environmental and physiological factors which affect progesterone concentrations.

This experiment has shown that the progesterone concentrations during Days 0 and 1 are associated with embryo loss; in particular, higher values are associated with improved survival. Such endogenous variation may account for some of the previously unexplained embryo mortality. Attempts to increase embryo survival in sheep by administration of progesterone during the luteal phase have produced inconsistent results. Davis et al. (1986) reported increased pregnancy rates, whereas Smith et al. (1985) observed no difference in embryo survival, after treatment with progesterone. The present experiment suggests that appropriate doses of supplementary progesterone around the time of mating may prove to be an alternative method for improving embryo survival. 
We thank Miss M. R. Thomson for experimental surgery; Mr J. C. Manson for the anaesthesia; Mr A. MacGregor and his staff for care of the sheep; Mr I. Swanston and NIAMDD for hormone preparations; and Dr J. E. T. Corrie for the anti-progesterone serum.

C.J.A. was in receipt of an AFRC research studentship during this experiment.

\section{References}

Ashworth, C.J. (1985) Maternal factors affecting early pregnancy in sheep. $\mathrm{Ph} . \mathrm{D}$. thesis, University of Edinburgh.

Ashworth, C.J., Sales, D.I. \& Wilmut, I. (1984) Patterns of progesterone secretion and embryonic survival during repeated pregnancies in Damline ewes. Proc. IOth Int. Cong. Anim. Reprod. \& A.I., Urbana, Communication No. 74.

Ashworth, C.J., Wilmut, I., Springbett, A.J. \& Webb, R. (1987) Effect of an inhibitor of $3 \beta$-hydroxysteroid dehydrogenase on progesterone concentrations and embryo survival in sheep. $J$. Endocr. 112, 205-213.

Baker, R.J. \& Nelder, J.A. (1978) The GLIM System, Release 3. Numerical Algorithms Group, Oxford.

Bedford, C.A., Harrison, F.A. \& Heap, R.B. (1972) The metabolic clearance rate and production rate of progesterone and the conversion of progesterone to $20 \alpha-$ hydroxypregn-4-en-3-one in the sheep. J. Endocr. 55, 105-108.

Cumming, I.A., Blockey, M.A. de B., Winfield, C.G., Parr, R.A. \& Williams A.H. (1975) A study of relationships of breed, time of mating, level of nutrition, and face cover to embryo survival in ewes. J. agric. Sci., Camb. 84, 559-565.

Davis, I.F., Kerton, D.J., Parr, R.A., White, M.B. \& Williams A.H. (1986) Hormone supplementation to increase fertility after uterine artificial insemination in ewes. Proc. Aust. Soc. Anim. Prod. 16, 171-173.

Edey, T.N. (1976) Embryo mortality. In Sheep Breeding, pp. 400-410. Eds G. J. Tomes, D. E. Robertson \& R. J. Lightfoot. New England University Press, Armidale.

England, B.G., Dahmer, M.K. \& Webb, R. (1981) Relationships between follicular size and antral fluid steroid concentrations at 3 stages of the estrous cycle in the ewe. Biol. Reprod. 24, 1068-1075.

Hanrahan, J.P. (1982) Selection for increased ovulation rate, litter size and embryo survival. Proc. 2nd Wld Congr. Genetics Applied to Livestock Production V, 294-309.

Kelly, R.W. (1984) Fertilisation failure and embryonic wastage. In Reproduction in Sheep, pp. 127-133. Eds D. R. Lindsay \& D. T. Pearce. Australian Academy of Science, Canberra.

Lapetina, E.G. (1982) Platelet activating factor stimulates the phosphatidylinositol cycle. J. biol. Chem. 257, 7314-7317.

Lee, C.N., Critser, J.K. \& Ax, R.L. (1985) Changes of luteinizing hormone and progesterone for dairy cows after gonadotropin-releasing hormone at first postpartum breeding. J. Dairy Sci. 68, 1463-1470.

Lightfoot, R.J. (1986) Effect of time of joining on reproductive wastage in Merino sheep. Proc. Aust. Soc. Anim. Prod. 16, 255-258.
Long, S.E. \& Williams, C.V. (1980) Frequency of chromosomal abnormalities in early embryos of domestic sheep (Ovis aries). J. Reprod. Fert. 58, 197-201.

MeNatty, K.P., Gibb, M., Dobson, C., Thurley, D.C. \& Findlay, J.K. (1981) Changes in the concentration of gonadotrophic and steroidal hormones in the antral fluid of ovarian follicles throughout the oestrous cycle of the sheep. Aust. J. biol. Sci. 34, 67-80.

Miller, B.G. \& Moore, N.W. (1976) Effects of progesterone and oestradiol on RNA and protein metabolism in the genital tract and on survival of embryos in the ovariectomized ewe. Aust. J. biol. Sci. 29, 565-573.

Nelder, J.A. \& Wedderburn, R.W.N. (1972) Generalized linear models. J. R. Statist. Soc. A 135, 370-384.

O'Neill, C. (1987) Embryo derived platelet activating factor: a preimplantation mediator of maternal recognition of pregnancy. Dom. Anim. Endocr. 4, 69-85.

O'Neill, C., Gidley-Baird, A.A., Pike, I.L. \& Saunders, D.M. (1987) A bio-assay for embryo derived platelet activating factor as a means of assessing quality and pregnancy potential for human embryos. Fert. Steril. 47, 969-975.

Parr, R.A., Davis, I.F., Fairclough, R.J. \& Miles, M.A. (1987) Overfeeding during pregnancy reduces peripheral progesterone concentration and pregnancy rate in sheep. J. Reprod. Fert. 80, 317-320.

Rhind, S.M., Chesworth, J.M. \& Robinson, J.J. (1978) A seasonal difference in ovine peripheral plasma prolactin and progesterone concentrations in early pregnancy and in the relationship between the two hormones. J. Reprod. Fert. 52, 79-81.

Smith, C., King, J.W.B., Nicholson, D., Wolf, B.T. \& Bampton, P.R. (1979) Performance of crossbred sheep from a synthetic dam line. Anim. Prod. 29, 1-9.

Smith, J.F., Farquar, P.A. \& Welch, R.A.S. (1985) Failure of progesterone administered mid-cycle to influence conception rate or embryonic mortality. Proc. Endocr. Soc. Aust. Suppl. 28, Abstr. 9.

Terrill, C.E. (1974) Reproductive cycles. In Reproduction in Farm Animals, pp. 265-274. Ed. E. S. E. Hafez. Lea \& Febiger, Philadelphia.

Webb, R., Baxter, G., Preece, R.D., Land, R.B. \& Springbett, A.J. (1985) Control of gonadotrophin release in Scottish Blackface and Finnish Landrace ewes during seasonal anoestrus. J. Reprod. Fert. 73, 369-378.

Wheeler, A.G., Baird, D.T., Land, R.B. \& Scaramuzzi, R.J. (1975) Increased secretion of progesterone from the ovary of the ewe during the preovulatory period. J. Reprod. Fert. 45, 519-522.

White, L.M., Keisler, D.H., Dailey, R.A. \& Inskeep, E.K. (1987) Characterization of ovine follicles destined to form subfunctional corpora lutea. J. Anim. Sci. 65, 1595-1601. 
Williams, A.H. \& Cumming, I.A. (1982) Inverse relationship between concentration of progesterone and nutrition in ewes. J. agric. Sci., Camb. 98, 517-522.

Wilmut, I. \& Sales, D.I. (1981) Effect of an asynchronous environment on embryo development in sheep. $J$. Reprod. Fert. 61, 179-184.

Wilmut, I., Sales, D.I. \& Ashworth, C.J. (1985a) The influence of variation in embryo stage and maternal hormone profiles on embryo survival in farm animals. Theriogenology 23, 107-119.
Wilmut, I., Sales, D.I. \& Ashworth, C.J. (1985b) Physiological criteria for embryo mortality: is asynchrony between embryo and ewe a significant factor? In The Genetics of Reproduction in Sheep, pp. 275-289. Eds R. B. Land \& D. Robinson. Butterworths, London.

Wilmut I., Ashworth, C.J. \& Sales, D.I. (1986) The influence of progesterone profile on embryo survival in ewes. In Embryonic Mortality in Farm Animals, pp. 135-141. Eds J. M. Sreenan \& M. G. Diskin. Martinus Nijhoff, The Hague.

Received 8 August 1988 